\title{
Chromosome spreading of associated transposable elements and ribosomal DNA in the fish Erythrinus erythrinus. Implications for genome change and karyoevolution in fish
}

\author{
Marcelo B Cioffi ${ }^{*}$, Cesar Martins², Luiz AC Bertollo ${ }^{1}$
}

\begin{abstract}
Background: The fish, Erythrinus erythrinus, shows an interpopulation diversity, with four karyomorphs differing by chromosomal number, chromosomal morphology and heteromorphic sex chromosomes. Karyomorph A has a diploid number of $2 n=54$ and does not have differentiated sex chromosomes. Karyomorph $D$ has $2 n=52$ chromosomes in females and $2 n=51$ in males, and it is most likely derived from karyomorph $A$ by the differentiation of a multiple $X_{1} X_{2} Y$ sex chromosome system. In this study, we analyzed karyomorphs $A$ and $D$ by means of cytogenetic approaches to evaluate their evolutionary relationship.

Results: Conspicuous differences in the distribution of the 5S rDNA and Rex3 non-LTR retrotransposon were found between the two karyomorphs, while no changes in the heterochromatin and 185 rDNA patterns were found between them. Rex3 was interstitially dispersed in most chromosomes. It had a compartmentalized distribution in the centromeric regions of only two acrocentric chromosomes in karyomorph A. In comparison, in karyomorph D, Rex3 was found in 22 acrocentric chromosomes in females and 21 in males. All 5S rDNA sites co-localized with Rex3, suggesting that these are associated in the genome. In addition, the origin of the large metacentric $Y$ chromosome in karyomorph $\mathrm{D}$ by centric fusion was highlighted by the presence of internal telomeric sites and $5 \mathrm{~S}$ rDNA/Rex3 sites on this chromosome.

Conclusion: We demonstrated that some repetitive DNAs (5S rDNA, Rex3 retroelement and (TTAGGG) $n$ telomeric repeats) were crucial for the evolutionary divergence inside E. erythrinus. These elements were strongly associated with the karyomorphic evolution of this species. Our results indicate that chromosomal rearrangements and genomic modifications were significant events during the course of evolution of this fish. We detected centric fusions that were associated with the differentiation of the multiple sex chromosomes in karyomorph $D$, as well as a surprising increase of associated $5 \mathrm{~S} \mathrm{rDNA} /$ Rex 3 loci, in contrast to karyomorph $\mathrm{A}$. In this sense, E. erythrinus emerges as an excellent model system for better understanding the evolutionary mechanisms underlying the huge genome diversity in fish. This organism can also contribute to understanding vertebrate genome evolution as a whole.
\end{abstract}

\section{Background}

Repetitive DNA sequences include tandemly-arrayed satellites, as well as minisatellites, microsatellites and dispersed repeats such as transposable elements (TEs) [1]. Satellite DNAs are organized as long arrays of head-

\footnotetext{
* Correspondence: mbello.ufscar@gmail.com

'Universidade Federal de São Carlos, Departamento de Genética e Evolução, São Carlos, SP, Brazil

Full list of author information is available at the end of the article
}

to-tail linked repeats. TEs are DNA segments capable of integrating into new locations in the genome, and they also mobilize non-autonomous sequences [2,3]. TEs and satellite DNAs are some of the most important components of the genome that contribute to genetic variations within and between species [4]. The possible functions of these repetitive DNAs have been the focus of several studies, and there are indications that they
C Biomed Central

() 2010 Cioffi et al; licensee BioMed Central Ltd. This is an Open Access article distributed under the terms of the Creative Commons Attribution License (http://creativecommons.org/licenses/by/2.0), which permits unrestricted use, distribution, and reproduction in any medium, provided the original work is properly cited. 
could play important roles at both the chromosomal and nuclear levels [5-8].

Fish genomes contain all known types of transposable elements: classical DNA transposons, miniature inverted-repeat transposable elements and retroelements, which include long terminal repeat (LTR) retrotransposons and non-LTR retrotransposons [9]. While DNA transposons move directly as DNA molecules from one genomic site to another, retroelements transpose via an RNA intermediate. Among retrotransposable elements, Rex is comprised of various families of transposable elements that are abundant in teleosts. Rex3, the first reverse transcriptase (RT)-encoding retrotransposon isolated from the melanoma fish model, Xiphophorus, is a non-LTR element related to the RTE family that shows wide distribution and different patterns of organization in the genomes of several fish species $[10,11]$.

The molecular organization and cytogenetic locations of repetitive DNAs, including rDNA repeats [12-18], satellite DNAs $[19,20]$, telomeric sequences $[18,21,22]$ and several classes of TEs $[2,3,23,24]$, have been analyzed in a large number of fish species. These studies have demonstrated the enormous potential that the investigation of repetitive DNAs offers toward extending our knowledge of karyotype differentiation and sex chromosome evolution in fish $[16,18,25-29]$. These genomic components are able to change the molecular composition of sex chromosomes and reduce the rate of recombination between them, which are crucial steps in the differentiation of sex chromosomes [30-33].

Erythrinus is a cytogenetically poorly studied genus inside the Erythrinidae family. Until now, classical cytogenetic analyses have only been conducted with the species, E. erythrinus. These have shown a karyotypic diversity among populations, with four currently identified karyomorphs (A to D) [34]. Karyomorph A is comprised of populations with $2 \mathrm{n}=54$ chromosomes, which have very similar karyotypic structures $(6 m+2 s t+46 a)$ and an absence of differentiated sex chromosomes. Karyomorphs $\mathrm{B}, \mathrm{C}$ and $\mathrm{D}$ share an $\mathrm{X}_{1} \mathrm{X}_{1} \mathrm{X}_{2} \mathrm{X}_{2} / \mathrm{X}_{1} \mathrm{X}_{2} \mathrm{Y}$ sex chromosome system, but they differ in their diploid number and chromosomal morphology. It has been proposed that a centric fusion between two non-homologous acrocentric chromosomes may have created the specific $\mathrm{Y}$ chromosome and, consequently, the unpaired $\mathrm{X}_{1}$ and $\mathrm{X}_{2}$ chromosomes in the male karyotypes. Karyomorph B has $2 n=54(6 \mathrm{~m}+2 \mathrm{st}+46 \mathrm{a})$ chromosomes in females and $2 n=53(7 m+2 s t+44 a)$ in males. Both karyomorphs $\mathrm{C}$ and $\mathrm{D}$ show $2 \mathrm{n}=52 / 51$ chromosomes but differ in their karyotypic formula, i.e., $6 \mathrm{~m}+2 \mathrm{sm}+$ $6 s t+38 a$ in females and $7 m+2 s m+6 s t+36 a$ in males of karyomorph $C$ and $4 m+2 s m+2 s t+44 a$ in females and $5 m+2 s m+2 s t+42 a$ in males of karyomorph D. The distinct chromosomal features found among isolated populations suggest the occurrence of several unnamed new species within this fish group [34].

In this report, new samples from allopatric populations of karyomorphs A and D were analyzed using new methodological approaches and molecular cytogenetic analyses to find useful new characteristics for comparative genomics at the chromosomal level and to provide insights into the karyoevolutionary pathways in this fish group. The results show that chromosomal rearrangements and genomic modifications were significant events during the course of evolution of this fish. Centric fusions were found to be clearly associated with the differentiation of the multiple sex chromosomes in karyomorph D. In addition, a surprising increase in the number of associated 5S rDNA/Rex3 loci was found in karyomorph $\mathrm{D}$, in contrast to karyomorph A.

\section{Results}

\section{Karyotyping and C-banding}

The two populations showed evidence of the general karyotypic structures of the Erythrinus species, with few biarmed chromosomes and a large number of acrocentric ones (Fig. 1). The sample from Penápolis-SP showed $2 n=54$ chromosomes $(6 m+2 s t+46 a)$ and lacked morphologically differentiated sex chromosomes, which is characteristic of karyomorph A. The samples from Natal-RN showed $2 \mathrm{n}=52$ chromosomes $(4 \mathrm{~m}+$ $2 \mathrm{sm}+2 \mathrm{st}+42 \mathrm{a}$ ) in females and $2 \mathrm{n}=51$ chromosomes $(5 \mathrm{~m}+2 \mathrm{sm}+2 \mathrm{st}+42 \mathrm{a})$ in males, with a multiple $\mathrm{X}_{1} \mathrm{X}_{1} \mathrm{X}_{2} \mathrm{X}_{2} / \mathrm{X}_{1} \mathrm{X}_{2} \mathrm{Y}$ sex chromosome system, which is characteristic of karyomorph D (Fig. 1). Conspicuous Cpositive bands were observed in the centromeric/pericentromeric region of several chromosomes, as well as in the telomeric region of some pairs, in both karyomorphs. A small but significant heterochromatic block was found in the interstitial region of the long arms of the $\mathrm{Y}$ and $\mathrm{X}_{1}$ chromosomes of karyomorph D (Fig. 1).

\section{Nucleotide sequences}

Nucleotide sequences were determined for the Rex3 clones to confirm that the PCR-isolated DNA fragments corresponded to copies of the retrotransposable element, Rex3. One of these sequences was deposited in GenBank under the accession number, GU989321. NCBI BlastN searches identified a similarity between the E. erythrinus Rex3 sequence and sequences found in fish from other distinct orders, such as Anguilliformes, Perciformes, Beloniformes, Cyprinodontiformes and Tetraodontiformes.

\section{Cytogenetic mapping of 185 and $5 S$ rDNAs, Rex3 and (TTAGGG) $_{n}$ telomeric repeats}

Double-FISH with $5 \mathrm{~S}$ and $18 \mathrm{~S}$ rDNAs showed a similar distribution pattern for the $18 \mathrm{~S}$ rDNA sites in both the 


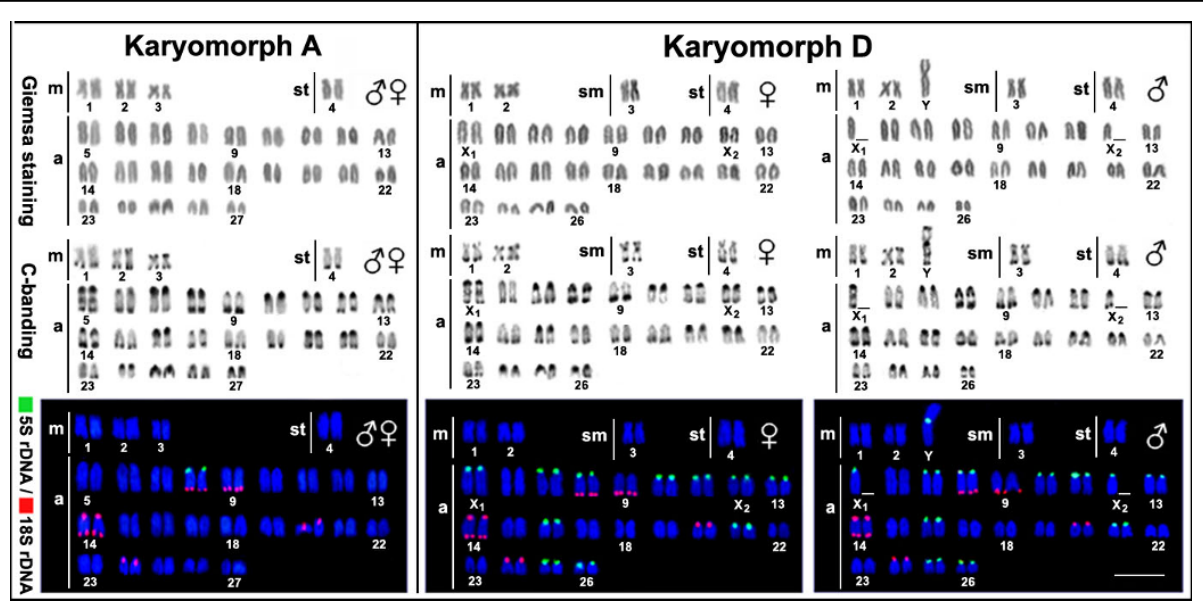

Figure 1 Karyotypes of males and females of Erythrinus erythrinus (karyomorphs A and D) under different cytogenetic analyses. The karyotypes, arranged by sequentially Giemsa-stained and C-banded chromosomes, were probed with 5S rDNA and 18S rDNA after a double-FISH analysis. Note the significant increase of $5 \mathrm{~S}$ rDNA sites in karyomorph D. m, metacentric chromosomes; sm, submetacentric chromosomes; st, subtelocentric chromosomes; a, acrocentric chromosomes. Bar $=5 \mu \mathrm{m}$.

A and D karyomorphs. Five acrocentric pairs with telomeric sites on the long or short arms were found. In addition, bitelomeric sites were found on pair no. 14. In contrast, a large difference was seen in 5S rDNA distribution. Karyomorph A showed only two 5S rDNA sites in the centromeric region of acrocentric pair no. 8 , which also bears a telomeric $18 \mathrm{~S}$ rDNA site on its long arm. Although karyomorph D shared the syntenic condition seen in karyomorph A, it showed a surprising increase in the number of $5 \mathrm{~S}$ rDNA sites, with 22 in females and 21 in males. These sites were all found in the centromeric region of acrocentric chromosomes except for a site in the metacentric $\mathrm{Y}$ chromosome in males (Fig. 1).

Double-FISH with 5S rDNA and Rex3 probes showed that Rex3 has an interstitial and dispersed distribution pattern along most chromosomes in both karyomorphs. In addition, $\operatorname{Rex} 3$ clusters were predominantly located in the centromeric regions and co-localized with heterochromatic blocks in both karyomorphs, which matches the 5S rDNA distribution pattern (Fig. 2).

Mapping of the (TTAGGG) $)_{n}$ telomeric repeats in males of karyomorph D showed the typically expected telomeric signals on both telomeres of all chromosomes. Interstitial telomeric sites (ITS) were located in the centromeric regions of the only submetacentric pair and on the largest metacentric Y chromosome (Fig. 3).

\section{Discussion}

Among Characiformes fish, which include the Erythrinidae family, the most frequent chromosomal number is $2 \mathrm{n}=54$, and this number may represent the basal diploid number of this order [35]. In this context, karyomorph A of E. erythrinus, which has a diploid number of $2 \mathrm{n}=54$, may have the most primitive karyotype found in the Erythrinus genus. This finding also takes into account the fact that differentiated sex chromosomes are absent in this karyomorph. Similarly, karyomorph D, which is most likely derived from karyomorph $\mathrm{A}$, shows a smaller diploid number due to chromosomal rearrangements and a well-differentiated multiple $\mathrm{X}_{1} \mathrm{X}_{1} \mathrm{X}_{2} \mathrm{X}_{2} / \mathrm{X}_{1} \mathrm{X}_{2} \mathrm{Y}$ sex chromosome system. However, despite differences in diploid numbers and the occurrence of differentiated sex chromosomes, karyomorphs $\mathrm{A}$ and $\mathrm{D}$ share a relatively similar karyotypic structure formed by several acrocentric and a few biarmed chromosomes with similarly distributed C-bands and $18 \mathrm{~S}$ rDNA sites. However, the repetitive 5S rDNA and Rex3 sequences have quite distinct distributions in the two karyomorphs.

A reduction in chromosome numbers often results from centric fusion rearrangements from acrocentric chromosomes. Based only on classical cytogenetic data, it was previously proposed that an initial centric fusion gave rise to the $\mathrm{X}_{1} \mathrm{X}_{1} \mathrm{X}_{2} \mathrm{X}_{2} / \mathrm{X}_{1} \mathrm{X}_{2} \mathrm{Y}$ sex system found in karyomorphs $\mathrm{B}, \mathrm{C}$ and $\mathrm{D}$ of E. erythrinus. Also, it was proposed that the differentiation of karyomorph $\mathrm{D}$ resulted from another centric fusion between two nonhomologous acrocentric chromosomes, which was the origin of the only submetacentric pair found in the karyotype. In addition, pericentric inversions completed this karyotypic differentiation by decreasing the number of metacentric chromosomes and increasing the number of acrocentric chromosomes [34]. Indeed, this karyomorphic differentiation in E. erythrinus has now been corroborated by our FISH mapping of repetitive DNA sequences (Fig. 4). 


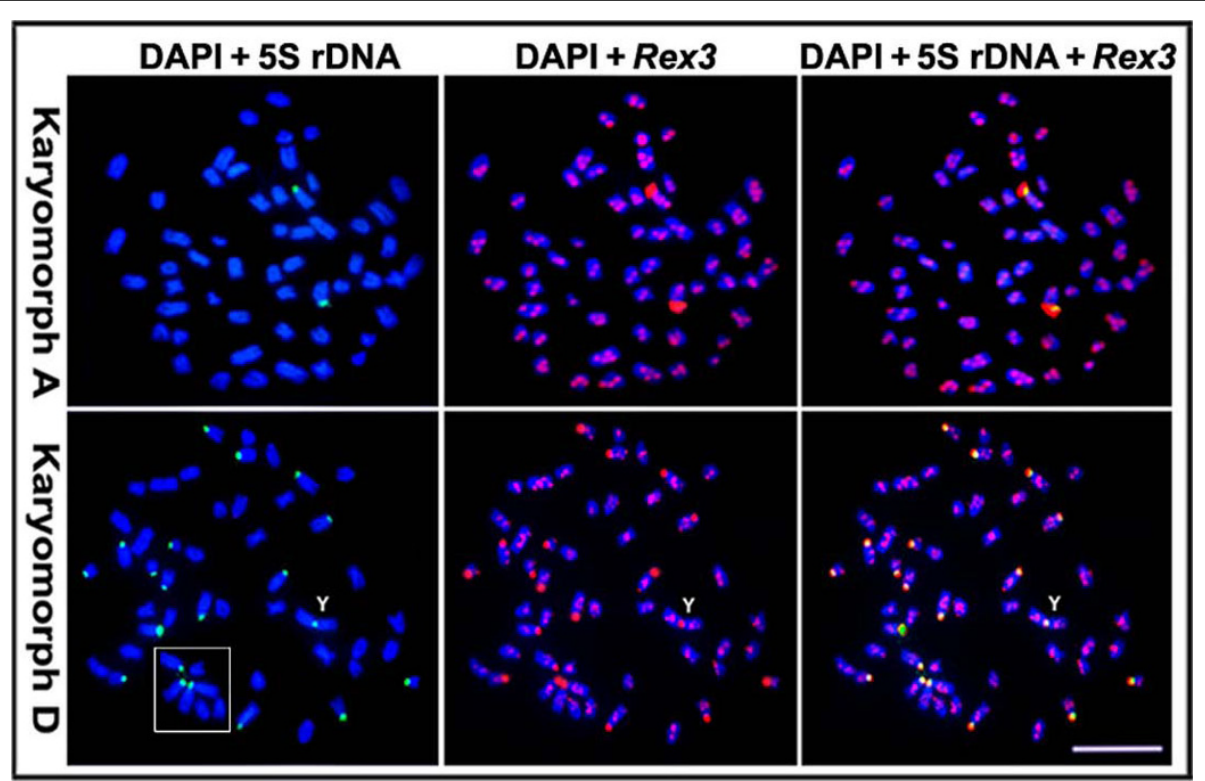

Figure 2 Metaphase plates of karyomorphs A and D of Erythrinus erythrinus showing the locations of the 5S rDNA and the Rex3 retroelement on the chromosomes using double-FISH analysis. Note the dispersed interstitial pattern of Rex3 in both karyomorphs and its co-localization with the $5 \mathrm{~S}$ rDNA on the centromeric region of the chromosomes. The box indicates the clear aggregation of some acrocentric chromosomes, which was seen in almost all chromosome preparations. The $\mathrm{Y}$ chromosome is indicated. Bar $=5 \mu \mathrm{m}$.

The chromosomal location of 5S rDNA, Rex3 and telomeric repeats clearly corroborates the centric fusions that occurred during the karyotypic differentiation of karyomorph D. The mapping of ITS in the centromeric region of the submetacentric pair highlights the centric fusion that was involved in the origin of this chromosome pair, which is not found in karyomorph A. Similarly, our results support the proposed origin for the largest metacentric $\mathrm{Y}$ chromosome from another centric fusion. As expected, (TTAGGG) ${ }_{n}$ repeats were also found in the centromeric region of this chromosome (Fig. 3). ITS have been found in the centromeric region of a large number of vertebrate species, suggesting that chromosomal rearrangements can occur without the loss of these telomeric sequences [36]. The general hypothesis that ITS may be remnants of chromosome rearrangements that occurred during genome evolution is supported by several investigations [37].

The location of $5 \mathrm{SrDNA} / \operatorname{Rex} 3$ sequences at the centromeric position of the $\mathrm{Y}$ chromosome is of particular relevance. These sequences were found in the centromeric region of several acrocentric chromosomes, including the ones proposed as $X_{1}$ (no. 5) and $X_{2}$ (no. 12) in the karyotype. The mapping of $5 \mathrm{~S}$ rDNA/Rex3 sites in the centromeric region of the $\mathrm{Y}$ chromosome suggests that this chromosome was created from a centric fusion of acrocentric pairs (nos. 5 and 12), which gave rise to the unpaired $X_{1}$ and $X_{2}$ chromosomes in the male karyotype (Figs. 1 and 2). Although the identification of the $\mathrm{X}_{2}$ chromosome remains unclear, the $\mathrm{X}_{1}$ chromosome appears to be the first acrocentric pair (no. 5) in this karyotype. This result is supported by the C-banding pattern in which a faint but informative $\mathrm{C}$-positive band occurs interstitially in corresponding regions of the $X_{1}$ chromosome and the long arm of the $\mathrm{Y}$ chromosome. It is probable that the same centric fusion also gave rise to the $\mathrm{X}_{1} \mathrm{X}_{2} \mathrm{Y}$ sex system in karyomorphs $B$ and $C$, since it appears to have originated before the divergence of these three karyomorphs [34] (Fig. 4).

The most remarkable difference between karyomorphs $\mathrm{A}$ and $\mathrm{D}$ was the distribution of $5 \mathrm{~S} \mathrm{rDNA} / \operatorname{Rex} 3$ sites over the chromosomes. While only a single chromosome pair was found to bear these sites in karyomorph A, a surprisingly large number of these sites were found in karyomorph D, with 22 sites in females and 21 in males. (Figs 2 and 4). Rex3, a non-LTR retrotransposon first isolated from the platyfish, Xiphophorus maculatus, shows a wide distribution among teleost fishes, where it appears to be associated with the evolution of different lineages [10,11]. Although Rex3 shows a preferential localization in the centromeric region of chromosomes in some fishes [23,24,38-40], it is widely scattered over all chromosomes in several Antarctic ice-fish species, with intense hybridization signals in some specific chromosomal regions [3]. Since a large majority of fish species studied until now harbor a low number of $5 \mathrm{~S}$ rDNA sites, with a few exceptions [41,42], the high 


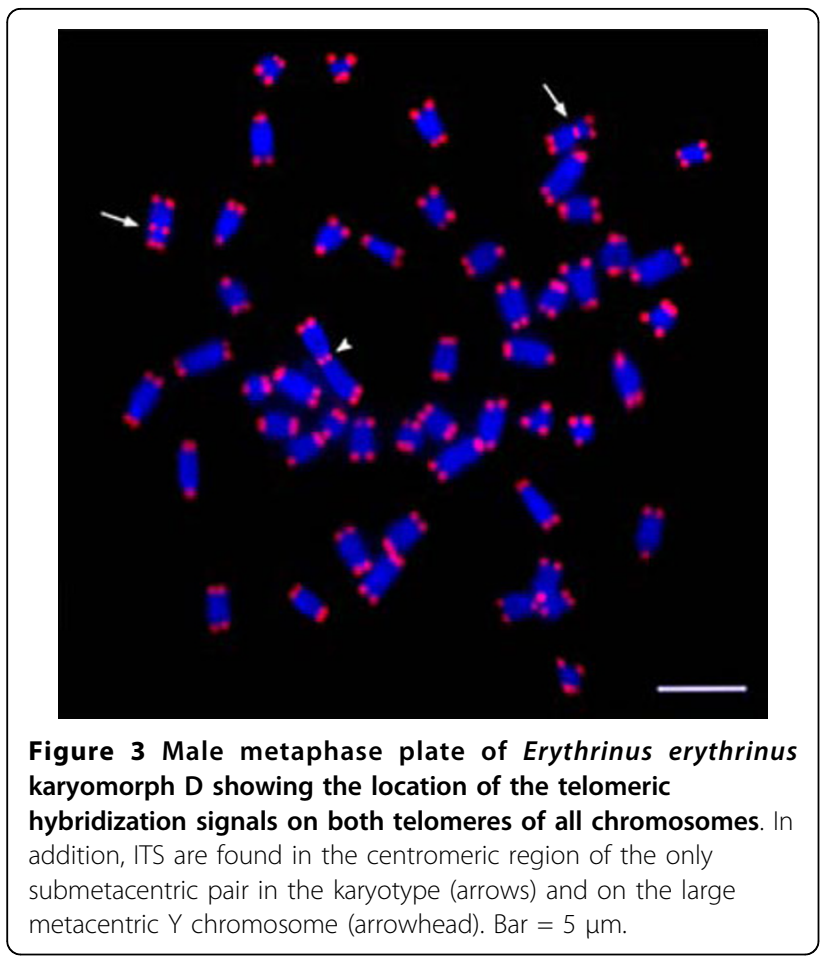

number of $5 \mathrm{~S}$ rDNA sites found in karyomorph $\mathrm{D}$ was an intriguing feature. According to the most probable hypothesis that karyomorph $\mathrm{D}$ represents a derivative form compared to karyomorph A, our results clearly show a huge dispersal of $5 \mathrm{~S} \mathrm{rDNA} / \operatorname{Rex} 3$ elements throughout the centromeric regions of the acrocentric chromosomes. We hypothesize that Rex3 may have inserted into $5 \mathrm{~S}$ rDNA sequences and that the $5 \mathrm{~S}$ rDNA-Rex3 complex moved and dispersed in the karyotype, although this hypothesis deserves further investigation and a molecular characterization. The clear association among the centromeric regions of the acrocentric chromosomes appears to be a favorable condition for this spreading (see details in Fig. 2).

Previous reports have suggested that the rDNA locus can serve as an ideal niche for the long-term survival of TEs [43], as seen in several organisms [44-46]. In situ hybridization revealed permanent clustering of different TEs in the NOR regions, as well as near or within clusters of 5S rDNA $[45,47]$. Hybridization on extended DNA fibers identified insertions of TEs inside the rDNA region, the overlap of rDNA and TE-enriched regions, and small fragments of rDNA inside TE-enriched regions. The presence of TEs in or around rDNA sites increases the possibility for recombination, which appears to be a common event in plant karyotype evolution [48]. In flowering plants, the distribution of $5 \mathrm{~S}$ rDNA genes is highly variable and may be partially explained by the activity of small non-autonomous retrotransposons named Cassandra [49]. It is currently believed that TEs tend to accumulate in heterochromatic regions because there are fewer genes and a weaker selection in the heterochromatin than in the euchromatin [50]. Recent studies have proposed that the activity of TEs is one possible source for rDNA movement $[43,48]$. Studies have also documented the ability of some classes of transposons to capture entire genes and move them to different parts of the genome [51,52].

Thus, considering the correlation between karyotype rearrangement and retrotransposon activity [3], and that rapid chromosomal evolution in some vertebrate lineages may be driven by the activity of repetitive sequences [53], we propose two probable alternatives during the karyotypic diversification of E. erythrinus, i.e., (i) the chromosomes of this species have undergone rearrangements during an evolutionary process mediated by retrotransposon activity or (ii) rearrangement events, including posterior mobilization of TEs, promoted the karyotypic differentiation among populations. However, it is difficult to state if a change in TE content or activity is the cause or the consequence of a speciation process because the true role of transposable elements in speciation is still a subject of large debate [6].

The frequent switching between different sex determination systems and the rapid evolution of sex chromosomes in fishes may also be linked to the formation of new species [54]. Recent comparative studies have revealed that teleost genomes have experienced a higher rate of gene-linkage disruption and chromosomal rearrangements compared to mammals, which may be linked to the apparent plasticity of their genomes $[55,56]$. Studies in fish models would therefore help in better understanding the molecular and evolutionary mechanisms underlying the huge genome diversity in this group, and these studies would also contribute to our understanding of vertebrate genome evolution.

\section{Conclusion}

Our in situ investigation of repetitive DNA sequences resulted in useful new characteristics for comparative genomics at the chromosomal level and provided insights into the karyoevolutionary pathways in E. erythrinus fish. Chromosomal rearrangements and genomic modifications were significant events during the course of karyoevolution of this fish. The spreading of associated transposable elements and ribosomal DNA in the genome and the differentiation of a multiple sex chromosome system was strongly associated with the evolution of karyomorph D. Considering the facts that fish occupy the basal position in the phylogeny of vertebrates, that they have a diversity of sex determining mechanisms and that many fish species lack heteromorphic sex chromosomes, E. erythrinus emerges as an excellent model system for better understanding the 


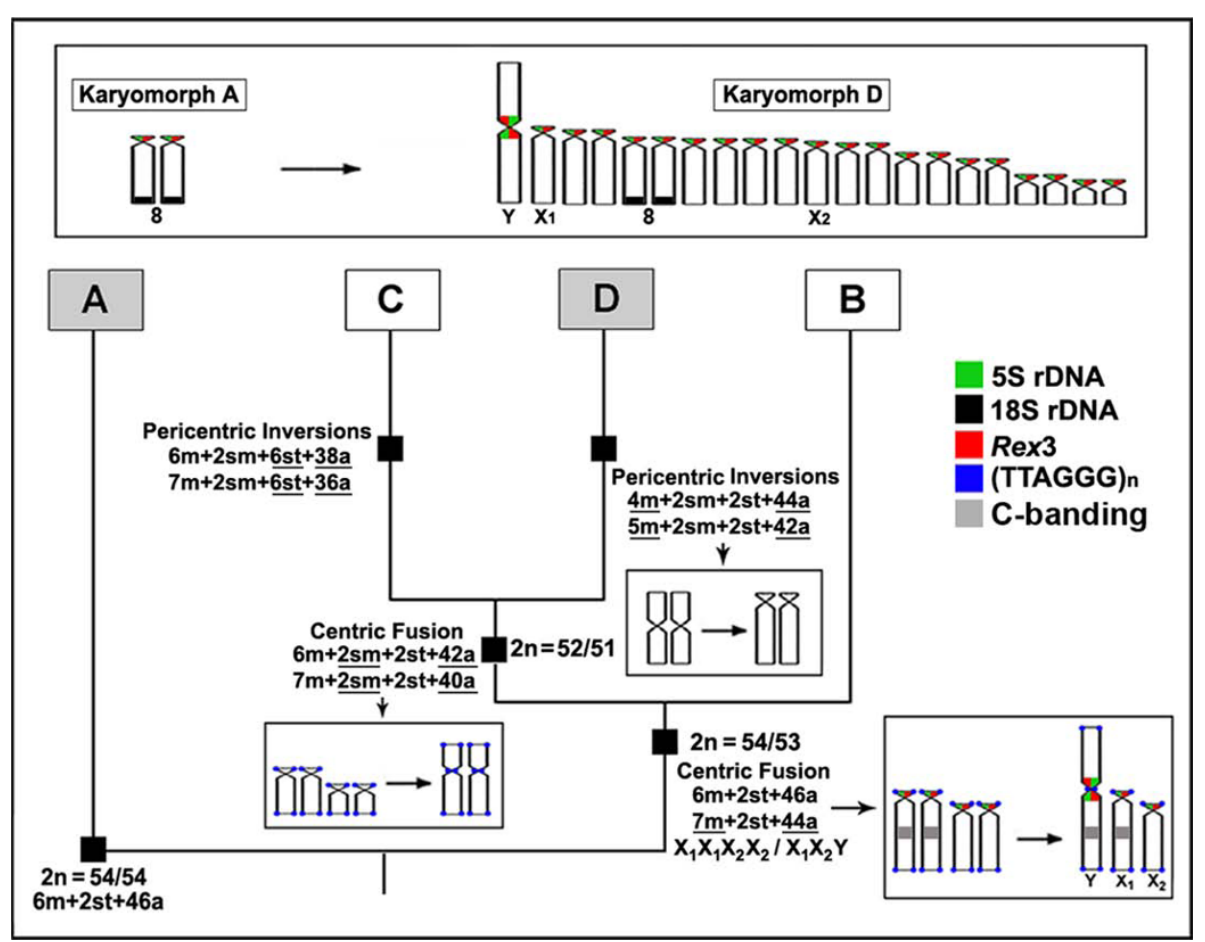

Figure 4 Overview of the evolutionary karyotypic pathways proposed for karyomorphs A-D of Erythrinus erythrinus on the basis of their karyotypic features and FISH mapping results for karyomorphs A and $\mathbf{D}$. The main chromosomal changes from the probable basal karyotype $(2 n=54 ; 6 m+2 s t+46 a)$ are underlined. The upward schematic figure illustrates the chromosomal distribution of the 185 rDNA and $5 \mathrm{~S} \mathrm{rDNA} /$ Rex3 sequences in karyomorph $\mathrm{A}$ and the expanded distribution of the latter sites in karyomorph $\mathrm{D}$, including the $\mathrm{Y}, \mathrm{X}_{1}$ and the probable $\mathrm{X}_{2}$ chromosome. The different colors represent the probes used for FISH.

evolutionary mechanisms underlying the huge genome diversity found among vertebrates.

\section{Methods}

Specimens, mitotic chromosome preparation, chromosome staining and karyotyping

In this study, we analyzed new samples from populations of karyomorphs A and D of the fish, E. erythrinus. We studied a total of 28 specimens (16 males and 12 females). Overall, 13 specimens ( 8 males and 5 females) of karyomorph A were obtained from Penápolis - São Paulo State, and 15 specimens (8 males and 7 females) of karyomorph D were obtained from Natal - Rio Grande do Norte State. These samples belong to distinct Brazilian hydrographic basins, which are isolated by thousands of kilometers.

Mitotic chromosomes were obtained from cell suspensions of the anterior kidney using the conventional airdrying method [57]. The experiments followed ethical conducts, and anesthesia was used prior to sacrificing the animals. The process was approved by the FAPESP committee under no. 2009/14881-3. Chromosomes were sequentially Giemsa-stained and C-banded using barium hydroxide to detect the C-positive heterochromatin [58].
Approximately 30 metaphase spreads were analyzed per specimen to determine the diploid chromosome number and karyotype structure. Images were captured by the CoolSNAP system software, Image Pro Plus, 4.1 (Media Cybernetics, Silver Spring, MD, USA), coupled to an Olympus BX50 microscope (Olympus Corporation, Ishikawa, Japan). The chromosomes were classified as metacentric (m), submetacentric ( $\mathrm{sm}$ ), subtelocentric (st) or acrocentric (a) according to the arm ratios [59].

\section{Chromosome probes}

Two tandemly-arrayed DNA sequences isolated from the genome of another Erythrinidae species, Hoplias malabaricus, were used. The first probe contained a $5 \mathrm{~S}$ rDNA repeat copy and included 120 base pairs (bp) of the 5S rRNA transcribing gene and $200 \mathrm{bp}$ of the nontranscribed spacer (NTS) [12]. The second probe corresponded to a 1,400-bp segment of the $18 \mathrm{~S}$ rRNA gene obtained via PCR from nuclear DNA [16]. The 5S and $18 \mathrm{~S}$ rDNA probes were cloned into plasmid vectors and propagated in DH5 $\alpha$ E. coli competent cells (Invitrogen, San Diego, CA, USA).

The retrotransposable element, $\operatorname{Rex3}$, was obtained by PCR directly from the genome of E. erythrinus using the 
primers Rex3f (5'-CGG TGA YAA AGG GCA GCC CTG) and Rex3r (5'-TGG CAG ACN GGG GTG GTG GT- $\left.3^{\prime}\right)$, as previously described [2,3]. The obtained nucleotide segment of the Rex3 transposon corresponds to the encoding domains $1,2,2 \mathrm{~A}, \mathrm{~A}$ and $\mathrm{B}$ of the RT gene [2]. A PCR-generated amplicon ( $500 \mathrm{bp})$ was isolated from a gel, purified with the Sephaglas Band Prep Kit (Pharmacia Biotech, Orsay, France) and ligated into the pGEM-T plasmid (Promega, Heidelberg, Germany). This plasmid was used to transform DH5 $\alpha$ E. coli competent cells (Invitrogen, San Diego, CA, USA). The positive clones were sequenced on an ABI Prism 377 DNA sequencer (Perkin Elmer, Branchburg, NJ, USA) with the ABI Prism BigDye Terminator Cycle Sequencing Ready Reaction Kit (Perkin Elmer, Branchburg, NJ, USA). The nucleotide sequence was subjected to Blastn [60] searches at the National Center for Biotechnology Information (NCBI) website http://www.ncbi.nlm.nih. gov/blast for the identification of any similarity of the isolated sequences to any known sequences from the nucleotide collection ( $\mathrm{nt} / \mathrm{nr}$ ), whole-genome shotgun reads (WGS), genomic survey sequences (GSS) and high-throughput genomic sequences (HTGS) in GenBank.

The 5S rDNA probe was labeled with biotin-14-dATP by nick translation according to the manufacturer's recommendations (BioNick ${ }^{\mathrm{Tm}}$ Labeling System; Invitrogen, San Diego, CA, USA). The $18 \mathrm{~S}$ rDNA and Rex3 probes were labeled by nick translation with DIG-11-dUTP according to the manufacturer's instructions (Roche, Mannheim, Germany).

A probe from the telomeric DNA sequence (TTAGGG) $_{\mathrm{n}}$ was generated by PCR (PCR DIG-Probe Synthesis Kit, Roche) in the absence of a template using $(\text { TTAGGG) })_{5}$ and (CCCTAA $)_{5}$ as primers [37].

Fluorescent in situ hybridization (FISH) was performed under high stringency conditions on mitotic chromosome spreads [61]. The metaphase chromosome slides were incubated with RNAse $(40 \mu \mathrm{g} / \mathrm{ml})$ for $1.5 \mathrm{~h}$ at $37^{\circ} \mathrm{C}$. After denaturation of chromosomal DNA in 70\% formamide $/ 2 \times \mathrm{SSC}$ at $70^{\circ} \mathrm{C}$, spreads were incubated in $2 \times \mathrm{SSC}$ for $4 \mathrm{~min}$ at $70^{\circ} \mathrm{C}$. The hybridization mixture $(2.5 \mathrm{ng} / \mu \mathrm{l}$ probes, $2 \mu \mathrm{g} / \mu \mathrm{l}$ salmon sperm DNA, 50\% deionized formamide, $10 \%$ dextran sulphate) was dropped on the slides, and the hybridization was performed overnight at $37^{\circ} \mathrm{C}$ in a moist chamber containing $2 \times$ SSC. Two posthybridization washes were carried out on a shaker $(150$ $\mathrm{rpm})$ at $37^{\circ} \mathrm{C}$. The first wash was in $2 \times \mathrm{SSC}, 50 \%$ formamide for $15 \mathrm{~min}$, followed by a second wash in $2 \times$ SSC for $15 \mathrm{~min}$. A final wash was performed at room temperature in $4 \times$ SSC for 15 min. Avidin-FITC (Sigma, St. Louis, MO, USA) was used for signal detection of the $5 \mathrm{~S}$ rDNA probe and anti-digoxigenin-rhodamine (Roche, Mannheim, Germany) for $18 \mathrm{~S}$ rDNA, Rex3 and
(TTAGGG) $)_{n}$ probes. One-color FISH was performed to detect (TTAGGG) ${ }_{n}$ repeats, while $5 \mathrm{~S} / 18 \mathrm{~S}$ rDNA and $5 \mathrm{~S}$ rDNA/Rex3 were detected by double-FISH. The chromosomes were counterstained with DAPI $(1.2 \mu \mathrm{g} / \mathrm{ml})$, mounted in Antifade solution (Vector, Burlingame, CA, USA) and analyzed in an epifluorescence microscope Olympus BX50 (Olympus Corporation, Ishikawa, Japan)

\section{Abbreviations}

2n: diploid number; DAPI: 4'-6-Diamidino-2-phenylindole; FITC: fluorescein isothiocyanate; FISH: fluorescent in-situ hybridization; ITS: interstitial telomeric sites; LTR: long terminal repeats; NCBI: National Center for Biotechnology Information; NOR: nucleolar organizer region; NTS: non-transcribed spacer; PCR: polymerase chain reaction; RT: reverse transcriptase; rDNA: ribosomal DNA; SSC: sodium chloride-sodium citrate buffer; TEs: transposable elements.

\section{Acknowledgements}

The authors are grateful to Dr. Christian Biémont for his helpful suggestions and critical review of the manuscript and to Dr. Wagner Franco Molina for supplying fish specimens. This work was supported by the Brazilian agencies FAPESP (Fundação de Amparo à Pesquisa do Estado de São Paulo), CNPq (Conselho Nacional de Desenvolvimento Científico e Tecnológico) and CAPES (Coordenação de Aperfeiçoamento de Pessoal de Nível Superior).

\section{Author details}

'Universidade Federal de São Carlos, Departamento de Genética e Evolução, São Carlos, SP, Brazil. ${ }^{2}$ UNESP- Universidade Estadual Paulista, Instituto de Biociências, Departamento de Morfologia, Botucatu, SP, Brazil.

\section{Authors' contributions}

MBC performed the experiments and drafted the manuscript. CM helped in analysis and drafted the manuscript. LACB designed and coordinated the study, and drafted and revised the manuscript. All authors read and approved the final manuscript.

Received: 10 May 2010 Accepted: 6 September 2010 Published: 6 September 2010

\section{References}

1. Jurka J, Kapitonov W, Pavlicek A, Klonowski P, Kohany O, Walichiewicz J: Repbase update, a database of eukaryotic repetitive elements. Cytogenet Genome Res 2005, 110:462-467.

2. Volff JN, Bouneau L, Ozouf-Costaz C, Fischer C: Diversity of retrotransposable elements in compact pufferfish genomes. Trends Genet 2003, 19:674-678.

3. Ozouf-Costaz C, Brandt J, Körting C, Pisavo E, Bonillo C, Contanceau JP, Volff JN: Genome dynamics and chromosomal localization of the nonLTR retrotransposons Rex 1 and Rex3 in Antarctic fish. Antarct Sci 2004, 16:51-57.

4. Biémont C: Within-species variation in genome size. Heredity 2008 , 101:297-298.

5. Larin Z, Fricker MD, Tyler-Smith C: De novo formation of several features of a centromere following introduction of an $Y$ alphoid $Y A C$ into mammalian cells. Hum Mol Genet 1994, 3:689-695.

6. Biémont C, Vieira C: Junk DNA as an evolutionary force. Nature 2006 , 443:521-524

7. Feschotte C, Pritham EJ: DNA Transposons and the evolution of eukaryotic genomes. Annu Rev Genet 2007, 41:331-368.

8. Longo MS, Carone DM, Marzelli M, NISC Comparative Sequencing Program, Green ED, O'Neill MJ, O’Neill RJ: Distinct retroelement classes define evolutionary breakpoints demarcating sites of evolutionary novelty. BMC Genomics 2009, 10:334.

9. Volff JN: Genome evolution and biodiversity in teleost fish. Heredity 2005, 94:280-294.

10. Volff JN, Korting C, Sweeney K, Schartl M: The non-LTR retrotransposon Rex3 from the fish Xiphophorus is widespread among teleosts. Mol Biol Evol 1999, 16:1427-1438. 
11. Malik HS, Eickbush TH: The RTE class of non-LTR retrotransposons is widely distributed in animals and is the origin of many SINEs. Mol Biol Evol 1998, 15:1123-1134.

12. Martins C, Ferreira IA, Oliveira C, Foresti F, Galetti PM Jr: A tandemly repetitive centromeric DNA sequence of the fish Hoplias malabaricus (Characiformes: Erythrinidae) is derived from 5 S rDNA. Genetica 2006, 127:133-141

13. Vicari MR, Artoni RF, Bertollo LAC: Comparative cytogenetics of Hoplias malabaricus (Pisces, Erythrinidae): A population analysis in adjacent hydrographic basins. Genet Mol Biol 2005, 28:103-110.

14. Vicari MR, Artoni RF, Moreira-Filho O, Bertollo LAC: Co localization of repetitive DNAs and silencing of major rRNA genes. A case report of the fish Astyanax janeiroensis. Cytogenet Genome Res 2008, 122:67-72

15. Cioffi MB, Martins C, Bertollo LAC: Comparative chromosome mapping of repetitive sequences. Implications for genomic evolution in the fish, Hoplias malabaricus. BMC Genetics 2009, 10:34.

16. Cioffi MB, Martins C, Centofante L, Jacobina U, Bertollo LAC: Chromosomal variability among allopatric populations of Erythrinidae Fish Hoplias malabaricus: mapping of three classes of repetitive DNAs. Cytogenet Genome Res 2009, 125:132-141.

17. Blanco DR, Lui RL, Bertollo LAC, Diniz D, Moreira-Filho O: Characterization of invasive fish species in a river transposition region: evolutionary chromosome studies in the genus Hoplias (Characiformes, Erythrinidae). Rev Fish Biol Fisheries 2009, 20:1-8.

18. Cioffi MB, Bertollo LAC: Initial steps in $X Y$ chromosome differentiation in Hoplias malabaricus and the origin of an $\mathrm{X} 1 \mathrm{X} 2 \mathrm{Y}$ sex chromosome system in this fish group. Heredity 2010.

19. Ferreira IA, Bertollo LAC, Martins C: Comparative chromosome mapping of $5 \mathrm{~S}$ rDNA and 5SHindIII repetitive sequences in Erythrinidae fish (Characiformes) with emphasis on Hoplias malabaricus "species complex". Cytogenet Genome Res 2007, 118:78-83.

20. Pazza R, Kavalco KF, Bertollo LAC: Chromosome polymorphism in Astyanax fasciatus (Teleostei, Characidae). 2 Chromosomal location of a satellite DNA. Cytogenet Genome Res 2008, 122:61-66.

21. Chew JSK, Oliveira C, Wright JM, Dobson MJ: Molecular and cytogenetic analysis of the telomeric (TTAGGG) ${ }_{n}$ repetitive sequences in the Nile tilapia, Oreochromis niloticus (Teleostei: Cichlidae). Chromosoma 2002, 111:45-52.

22. Sola L, De Innocentiis S, Gornung E, Papalia S, Rossi AR, Marino G, De Marco P, Cataudella S: Cytogenetic analysis of Epinephelus marginatus (Pisces: Serranidae), with the chromosome localization of the $18 \mathrm{~S}$ and 5 $\mathrm{S}$ rRNA genes and of the (TTAGGG) $n$ telomeric sequence. Marine Biol 2000, 137:47-51.

23. Mazzuchelli J, Martins C: Genomic organization of repetitive DNAs in the cichlid fish Astronotus ocellatus. Genetica 2009, 136:461-469.

24. Teixeira WG, Ferreira IA, Cabral-de-Mello DC, Mazzuchelli J, Valente GT, Pinhal $D$, Poletto $A B$, Venere $P C$, Martins $C$ : Organization of repeated DNA elements in the genome of the cichlid fish Cichla kelberi and its contributions to the knowledge of fish genomes. Cytogenet Genome Res 2009, 125:224-234

25. Nanda I, Feichtinger W, Schmid M, Schroder JH, Zischler H, Epplen JC: Simple repetitive sequences are associated with differentiation of the sex chromosomes in the guppy fish. J Mol Evol 1990, 30:456-462.

26. Nanda I, Volff JN, Weis S, Körting C, Froschauer A, Schimd M, Schartl M: Amplification of a long terminal repeat-like element on the $Y$ chromosome of the platyfish, Xiphophorus maculates. Chromosoma 2000, 109:173-180.

27. Nanda I, Kondo M, Hornung U, Asakawa S, Winkler C, Shimizu A, Shan Z Haaf T, Shimizu N, Shima A, Schimd M, Scharrl M: A duplicated copy of DMRT1 in the sex determining region of the $Y$ chromosome of the medaka, Oryzias latipes. Proc Natl Acad Sci USA 2002, 99:11778-11783.

28. Stein J, Phillips RB, Devlin RH: Identification of the $Y$ chromosome in Chinook salmon (Oncorhynchus tshawytscha). Cytogenet Cell Genet 2001, 92:108-110.

29. Parise-Maltempi PP, Martins C, Oliveira C, Foresti F: Identification of a new repetitive element in the sex chromosomes of Leporinus elongatus (Teleostei: Characiformes: Anostomidae): new insights into the sex chromosomes of Leporinus. Cytogenet Genome Res 2007, 116:218-223.

30. Liu ZY, Moore PH, Ma H, Ackerman CM, Ragiba M, Yu Q, Pearl HM, Kim MS, Charlton JW, Stiles Jl, Zee FT, Peterson AH, Ming R: A primitive $Y$ chromosome in papaya marks incipient sex chromosome evolution. Nature 2004, 427:348-352

31. Charlesworth D, Charlesworth B, Marais G: Steps in the evolution of heteromorphic sex chromosomes. Heredity 2005, 95:118-128.

32. Marchal JA, Acosta MJ, Bullejos M, Puerma E, Díaz de la Guardia R Sánchez A: Distribution of L1-retroposons on the giant sex chromosomes of Microtus cabrerae (Arvicolidae,Rodentia): functional and evolutionary implications. Chromosome Res 2006, 14:177-186.

33. Kejnovsky E, Hobza R, Cermák T, Kubát Z, Vyskot B: The role of repetitive DNA in structure and evolution of sex chromosomes in plants. Heredity 2009, 102:533-541.

34. Bertollo LAC, Oliveira C, Molina WF, Margarido VP, Fontes MS, Pastori MC, Falcão JN, Fenocchio : Chromosome evolution in the erythrinid fish, Erythrinus erythrinus (Teleostei: Characiformes). Heredity 2004, 93:228-233.

35. Oliveira C, Almeida-Toledo LF, Foresti F: Karyotypic evolution in Neotropical fishes. In Fish cytogenetics. Edited by: Pisano E, Ozouf-Costaz C, Foresti F, Kappor BG. Enfield NH, USA: Science Publisher; 2007:111-164.

36. Meyne J, Ratliff RL, Moyzis RK: Conservation of the human telomere sequence $($ TTAGGG) $\mathrm{n}$ among vertebrates. Proc Natl Acad Sci USA 1989, 86:7049-7053.

37. Ijdo JW, Wells RA, Baldini A, Reeders ST: Improved telomere detection using a telomere repeat probe (TTAGGG) ${ }_{n}$ generated by PCR. Nucleic Acids Res 1991, 19:4780.

38. Dasilva C, Hadji H, Ozouf-Costaz C, Nicaud S, Jaillon O, Weissenbach J, Crollius HR: Remarkable compartmentalization of transposable elements and pseudogenes in the heterochromatin of the Tetraodon nigroviridis genome. Proc Natl Acad Sci USA 2002, 99:1636-1641.

39. Bouneau L, Fisher C, Ozouf-Costaz C, Froschauer A, Jaillon O, Coutanceau JP, Korting C, Weissenbach J, Bernot A, Volff JN: An active Non-LTR retrotransposon with tandem structure in the compact genome of the pufferfish Tetraodon nigroviridis. Genome Res 2003, 13:1686-1695.

40. Gross MC, Schneider CH, Valente GT, Porto JIR, Martins C, Feldberg E: Comparative cytogenetic analysis of the genus Symphysodon (Discus Fishes, Cichlidae): chromosomal characteristics of retrotransposons and minor ribosomal DNA. Cytogenet Genome Res 2009, 127:43-53.

41. Affonso PRAM, Galetti PM Jr: Chromosomal diversification of reef fishes from genus Centropyge (Perciformes, Pomacanthidae). Genetica 2005, 123:227-233

42. Poletto $A B$, Ferreira $I A$, Martins $C$ : The $B$ chromosome of the cichlid fish Haplochromis obliquidens harbors 18 S rRNA genes. BMC Genetics 2010, 11:1-8.

43. Zhang $X$, Eickbush MT, Eickbush TH: Role of recombination in the longterm retention of transposable elements in rRNA gene loci. Genetics 2008, 180:1617-1626.

44. Eickbush $T H:$ R2 and related site-specific non-long terminal repeat retrotransposons. In Mobile DNA II. Edited by: Craig NL, Craigie R, Gellart M, Lambowitz AM. Washington DC: American Society of Microbiology; 2002:813-835.

45. Belyayev A, Raskina O, Nevo E: Variability of Ty3 gypsy retrotransposons chromosomal distribution in populations of two wild Triticeae species. Cytogenet Genome Res 2005, 109:43-50.

46. Ye J, Eickbush TH: Chromatin structure and transcription of the R1- and R2-inserted rRNA genes of Drosophila melanogaster. Mol Cell Biol 2006, 26:8781-8790.

47. Raskina O, Belyayev A, Nevo E: Quantum speciation in Aegilops: molecular cytogenetic evidence from rDNA clusters variability in natural populations. Proc Natl Acad Sci USA 2004, 101:14818-14823.

48. Raskina O, Barber JC, Nevo E, Belyayev A: Repetitive DNA and chromosomal rearrangements: speciation-related events in plant genomes. Cytogenet Genome Res 2008, 120:351-357.

49. Kalendar R, Tanskanen J, Chang W, Antonius K, Sela H, Peleg O, Schulman A: Cassandra retrotransposons carry independently transcribed 5 S RNA. Proc Natl Acad Sci USA 2008, 105:5833-5838.

50. Venner S, Feschotte C, Biémont C: Dynamics of transposable elements: Towards a community ecology of the genome. Trends Genet 2009, 25:317-323.

51. Jiang N, Bao Z, Zhang X, Eddy SR, Wessler SR: Pack-MULE transposable elements mediate gene evolution in plants. Nature 2004, 431:569-573. 
52. Lai Z, Nakazato T, Salmaso M, Burke JM, Tang S, Knapp SJ, Rieseberg LH: Extensive chromosomal repatterning and the evolution of sterility barriers in hybrid sunflower species. Genetics 2005, 171:291-303.

53. Wichman HA, Payne CT, Ryder OA, Hamilton MJ, Maltbie M, Baker RJ: Genomic distribution of heterochromatic sequences in equids: implications to rapid chromosomal evolution. J Hered 1991, 82:369-377.

54. Barske LA, Capel B: Blurring the edges in vertebrate sex determination. Curr Opin Genet Dev 2008, 18:499-505.

55. Ravi V, Venkatesh B: Rapidly evolving fish genomes and teleost diversity. Curr Opin Genet Dev 2008, 18:544-550.

56. Venkatesh B: Evolution and diversity of fish genomes. Curr Opin Genet Dev 2003, 13:588-592.

57. Bertollo LAC, Takahashi CS, Moreira-Filho O: Cytotaxonomic considerations on Hoplias lacerdae (Pisces, Erythrinidae). Brazil J Genet 1978, 1:103-120.

58. Sumner AT: A simple technique for demonstrating centromeric heterochromatin. Exp Cell Res 1972, 75:304-306

59. Levan A, Fredga K, Sandberg AA: Nomenclature for centromeric position on chromosomes. Hereditas 1964, 52:201-220.

60. Altschul SF, Gish W, Miller W, Myers EW, Lipman DJ: Basic local alignment search tool. J Mol Biol 1990, 215:403-410.

61. Pinkel D, Straume T, Gray J: Cytogenetic analysis using quantitative, high sensitivity, fluorescence hybridization. Proc Natl Acad Sci USA 1986, 83:2934-2938.

doi:10.1186/1471-2148-10-271

Cite this article as: Cioffi et al:: Chromosome spreading of associated transposable elements and ribosomal DNA in the fish Erythrinus erythrinus. Implications for genome change and karyoevolution in fish. BMC Evolutionary Biology 2010 10:271.

\section{Submit your next manuscript to BioMed Central and take full advantage of:}

- Convenient online submission

- Thorough peer review

- No space constraints or color figure charges

- Immediate publication on acceptance

- Inclusion in PubMed, CAS, Scopus and Google Scholar

- Research which is freely available for redistribution

Submit your manuscript at www.biomedcentral.com/submit 